\title{
Research on the exploration and development of teacher management model with agricultural characteristics
}

\author{
Dichen Shen \\ Jilin Agricultural University, Jilin, Changchun, 130118 China \\ 781911388@qq.com
}

\begin{abstract}
With the rapid development of China's higher education by the elite education stage to the mass education stage, the rapid expansion of the scale of higher agricultural colleges and universities, the relative lack of teachers. A large number of young teachers in the higher agricultural colleges and universities, and become the main force of teachers. Young teachers as the main force of teachers in Colleges and universities, the teaching ability, the relationship between the teaching quality and the quality of higher agricultural colleges and universities, the relationship between the development of higher agricultural institutions in the future, the relationship with the socialist new rural construction. Therefore, it is very important to study the cultivation of young teachers in Colleges and universities.
\end{abstract}

Keywords: agriculture; teachers; management model; exploration.

\section{Introduction}

The success or failure of the school in the teacher, only the teacher education life glow the fresh vitality, can realize to the student life the cultivation and the mold. However, the old teacher management idea, the model has restricted the development of teachers; it is difficult to guide the implementation of the new curriculum reform. Therefore, the reconstruction of teacher management mode, so as to adapt to the needs of teaching, and promote the development of the school, to become the focus of school management. So, how to build a new teaching management model? After two years of study, thinking and exploration, to reform the new ideas, new ideas for guiding ideology, the reform of the original teacher management mechanism, integrated teaching management resources, deepen the concept of harmonious management, explore a new type of teaching management model development of teacher's management model.

\section{Construct the participatory teaching and research management model}

The new curriculum reform calls for the classroom teaching is the life vigor of the teachers and students, is the teachers' leading, the establishment of the students' main body, is the "three dimensions" of the implementation. So we have changed the inspection and appraisal management mode, and from the examination to the organization of the teaching preparation, the teaching of knowledge in the classroom, the teaching of the course, the teaching of the course, the teaching task, the teaching task, the teaching of the course. Mainly adopted the following specific management mechanism:

(1) The establishment of participatory research management mechanism.

Construction of "discovery problem - organizational team - learning preparation, design and implementation of the design and implementation of reflection". Through theoretical learning; dialogue; teacher interaction; interaction between teachers and leadership; held stimulating --- music thinking of classroom teaching forum and seminar activities promote the effectiveness of school-based teaching and research, promote the professional growth of teachers. The implementation of the model, improve the teaching behavior, our school this year was rated as advanced school based teaching and research unit.

(2) The establishment of participatory planning management mechanism.

Constructs the collective lesson preparation mode which takes "teaching question - teaching design - teaching action - the teaching reflection" as the main body. Reform the way of preparing for 
lessons, change the teaching plan to the teaching design; reform the way of preparing for the lesson plan, use case preparation method, reflect the research form, and let the teacher develop the curriculum resources, improve the teachers' professional quality.

(3) Establish a lesson as the carrier of the action research management mechanism.

Around our school arousing the interest -- Thinking music school-based theme, the establishment of "behind the first point, full participation, gradually promote the school-based teaching research" action research system. Attach importance to the combination of professional guidance, cooperation and practice. To choose the initiative, the education theory is deep, and to participate in the research of the active high. Research mainly through "action - Research - practice" three processes. Teachers in independent lessons, classes, lessons, course, reflection and adjustment; (that is, found problem) and professional researchers rated course, reflection, cooperation study preparation, adjustment to improve, class observation (team organization; learning readiness; design and Implementation); last observation discussion and reflection accumulation and sublimation of research, summed up the exchange.

Through the research of the above three processes, the practical problems encountered in the teaching of teachers are solved, and the teaching effect is improved obviously. Through the teaching action research and the reflection of his own teaching, the teacher's understanding of the teaching process and the self-recognition greatly improved, resulting in the independent development of power, the formation of the ability of self-development. Cultivate the spirit of cooperation, so that teachers establish a strong sense of teaching and learning, and self-confidence, so that teachers in the practice of education in the growing. Through the above measures, a year, our school has 10 classes by district level awards, 18 papers by the national, city level awards.

\section{Build the ladder type training management mechanism}

Teachers' professionalization is a special education system and management system, which is a special professional requirements and professional conditions of teachers' occupation. Teacher's specialization is a lifelong learning process, is a continuous process of solving the problem, is a teacher's professional ideal, professional ethics, professional emotion, social responsibility is constantly mature, continuous improvement, continuous innovation process. But in the face of uneven teachers, how to promote the common development of all teachers, can achieve the continuous development of teachers themselves? Based on this, we have tried the ladder type school based training model, received the obvious results.

(1) Outside the school, the school building, building a ladder type of school based training model. "Outside the Box, jade". A wide range of learning new curriculum theory, to listen to the advice of experts, can make the school teaching work less detours, less error. To see this, our school to broaden the channels, spared no expense to other school, attend overseas study and training, hire experts at all levels and people to guide the work of school, consolidate the foundation of school-based training.

Our professional spirit of teachers, professional knowledge and professional ability conducted an investigation, in a timely manner to all the teachers are analyzed and feedback, guidance of all teachers to develop a "personal professional development plan", "four threes No.3" ladder type training mode is determined: building professionals "four grid level" - that is, new teachers into the lattice; upgrading of young teachers; fixed backbone teacher's style and middle-aged teachers training. Laying of professional talents of road function: the teaching basic skills; teaching ability and teaching foundation work, establish "three centered" teaching idea: that with infatuation for education and teaching the child, teacher's patience. Build "three" that is to learn the platform, the practice of the stage, showing the terrace. The implementation of teacher professional development of the three step strategy, sub stages, subs levels of professional training. Determined to cultivating new teachers and teachers, the backbone of ascension as training focus, seize the young teachers' aspect of amplification, seize the backbone teachers training system, compliance weaknesses in the lessons and information technology. Using the highlight and experience of the old teachers to analyze and study, set up their 
own style of teacher development ideas. Pay attention to the creative potential of the backbone teachers, strengthen the main role of the backbone teachers, explore the role and lead role, will be the backbone of the training process into a new curriculum training resources of the formation process, the overall level of teachers to improve the overall level.

(2) With the times, the renewal idea, the creation of effective participation in the training mechanism.

The cultivation of talents should be based on self-training. School development needs talent, but where to come from? The key is to start from the school sustainable development strategy, to build a suitable for the development of the school personnel training base, the establishment of the training of personnel training mechanism.

\section{Build a growth oriented evaluation management system}

As the development of anything, the professional development of teachers also need to protect the system. The establishment of teacher self-rating, the principal, teachers, students and parents to participate in the evaluation system, so that teachers from various sources of information, and constantly improve the teaching level, and promote the continuous development of teachers.

(1) Implementation of the "growth model" multiple evaluation strategy.

Pay attention to applying the concept of the evaluation of the development of and for teachers to study and work to carry out "five assessment activities, the account management to promote the teacher self-growth, namely in the form of field diagnostics of self-assessment, peer assessment, reviews and in the form of questionnaires and interviews, student assessment, parents' assessment, the evaluation should be teachers to pay more attention to the progress and development, so as to promote the improvement of teachers' quality. Pay attention to students and parents' evaluation of teachers' teaching.

School teaching management staff held a forum to investigate teachers' education and teaching behavior, so that students to teach teachers to evaluate; each semester to carry out "Teaching Open Day" activities, parents to visit the classroom, the school to provide subject teaching evaluation criteria, please listen to the parents. These two activities to collect information and teaching management recommendations for direct feedback to teachers. Let the teachers diagnose and reflect on their teaching behavior. Through the evaluation of various forces, the teacher can get the information from many channels to improve the teaching behavior, so as to continuously improve the teaching level.

(2) The implementation of quantitative and qualitative evaluation system.

Teacher education evaluation is a complex multilateral system, the evaluation is correct, the praise is practical, the criticism is appropriate, it will receive positive effect, and vice versa. Therefore, in the teaching evaluation management, it is not only to carry out the accurate evaluation, but also to carry on the fuzzy evaluation. For example, the evaluation of classroom teaching should take the way of quantitative evaluation; the main reason is that the teaching of the classroom has the characteristics of scientific nature. Qualitative and fuzzy evaluation of the quality of teachers. Because the teacher's job is a creative work. The evaluation should pay attention to give full scope to the talents, to put the teachers in the appropriate position, just try your best to do, it is necessary to affirm the paid labor, it should be commended, respected, self-value can be achieved, work enthusiasm will be excitation.

\section{Summary}

The development of teacher management model is characterized by: the development of teachers for the purpose, the development of teacher development, is conducive to the development of the school management strategy, the formation of all for the development of teachers and teaching and research model, training mechanism and evaluation system. To dilute the "conductor" role, and enhance the "designer" role, starting point and end point is to promote the development of teachers. In order to improve the quality and professional level of teachers as the goal, to teach the scientific 
research as the guide, to practice research as the focus, the teacher's needs as the content, and effectively for the teacher growth and professional development to lay a solid foundation.

As students' growth is his own thing, the teacher's professional development is the process of self - improvement and self - development in the teaching management. Therefore, using scientific methods, the development of innovative teaching management, will promote the development of teachers, bring the development of the school.

\section{Reference}

[1] Xi Xin, thinking of the management of university teachers in our country under the new situation, "Journal of West Anhui University" in 200303

[2] Zhang Chenghua, the game analysis of university teachers management, "Journal of Taiyuan Normal University (NATURAL SCIENCE EDITION)" 200304

[3] Han Zhongchun, the study of the motivation of university teachers management work, "the North economic and trade" in 200403

[4] Zhu Yongdong, Zhao Dongmei attached importance to the role of psychological contract in the management of college teachers, "Journal of Cangzhou Teachers College" in 200501

[5] Lu Yongming, the flexible management of university teachers, the high education forum in 2006 01

[6] Huang Yuexin, psychological contract, the cornerstone of university teachers management, "the Journal of the Hunan Academy of social science" in 200601

[7] Yang Qi, the construction of a good psychological contract in the management of university teachers, "scientific and technological information (Academic Research)" in 200610

[8] Lin Mengtao, the construction of university teachers management culture, "Journal of Mudanjiang Normal College (PHILOSOPHY AND SOCIAL SCIENCE EDITION)" 200703 